\title{
"SONG OF MYSELF," SECTION 1, IN FIFTEEN LANGUAGES
}

\section{SONG OF MYSELF}

I celebrate myself, and sing myself,

And what I assume you shall assume,

For every atom belonging to me as good belongs to you.

I loafe and invite my soul,

I lean and loafe at my ease observing a spear of summer grass.

My tongue, every atom of my blood, form'd from this soil, this air, Born here of parents born here from parents the same, and their parents the same, I, now thirty-seven years old in perfect health begin,

Hoping to cease not till death.

Creeds and schools in abeyance,

Retiring back a while sufficed at what they are, but never forgotten,

I harbor for good or bad, I permit to speak at every hazard,

Nature without check with original energy. 


\section{Chinese:}

\section{我自己的歌}

我赞美我自己,歌唱我自己，

我承担的你也将承担,

因为属于我的每一个原子也同样属于你。

我闲步,还邀请了我的灵魂,

我俯身悠然观察着一片夏日的草叶。

我的舌,我血液的每个原子, 是在这片土壤、这个空气

里形成的,

我是生在这里的父母生下的, 父母的父母也是在这里生下

的,他们的父母也一样,

我, 现在三十七岁,一开始身体就十分健康,

希望永不终止, 直到死去。

信条和学派暂时不论,

且后退一步, 明了它们当前的情况已足, 但也决不是忘 记,

不论我从善从恶, 我允许随意发表意见,

顺乎自然,保持原始的活力。 


\section{French:}

\section{CHANT DE MOI-MÊME}

Je me célèbre et me chante moi-même,

Et ce que je prends à mon compte, tu le prendras à ton compte,

Car chaque atome qui m'appartient, t'appartient aussi bien à toi.

Je muse et j'invite mon âme,

Je me penche et muse à mon aise tout en observant un brin d'herbe.

Ma langue, chaque atome de mon sang, faits de ce sol, de cet air, Né ici de parents nés ici de même, et leurs parents de même, Agé maintenant de trente-sept ans, en parfaite santé, je commence, Espérant ne plus cesser jusqu'à ma mort.

Ecoles et credos provisoirement suspendus,

S'effaçant un moment, satisfaits d'eux-mêmes, mais jamais oubliés,

Pour le bien ou pour le mal, je donne asile à la Nature, quels que soient les risques, je lui permets de s'exprimer,

Sans frein, avec son énergie originelle.

Roger Asselineau (1966) 
German:

\section{GESANG VON MIR SELBST}

Ich feiere mich selbst und singe mich selbst,

Und was ich mir anmaße, sollst du dir anmaßen,

Denn jedes Atom, das mir gehört, gehört auch dir.

Ich schlendre und lade meine Seele zu Gaste,

Ich lehne und schlendre nach meinem Behagen,

Einen Halm des Sommergrases betrachtend.

Meine Zunge, jedes Atom meines Bluts geformt aus diesem Boden, dieser Luft;

Geboren hier von Eltern, die hier geboren wurden von gleichen Eltern, und diese von gleichen Eltern,

Ich, siebenunddreißig Jahre alt, in vollkommener Gesundheit, beginne

Und hoffe nicht aufzuhören bis zum Tod.

Glauben und Schulen im Hintergrund,

Sie weichen für eine Weile zurück mit dem, was sie sind, doch nie vergessen,

Ich beherberge Gut und Böse, ich lasse reden auf jede Gefahr,

Natur ohne Zwang mit ursprünglicher Kraft.

Hans Reisiger (1922) 
Greek:

\section{TO TPAГOY I TOY EAYTOY MOY}

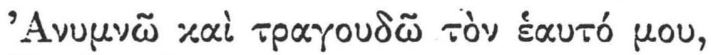

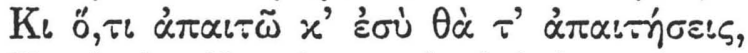

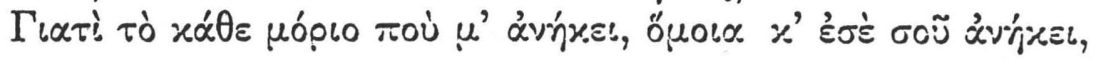

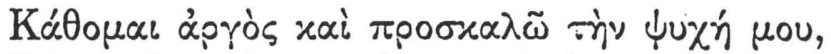

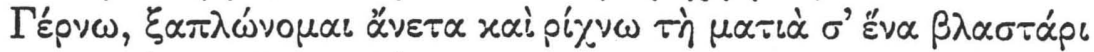

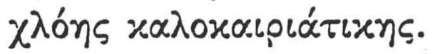

Mè

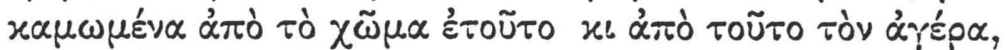

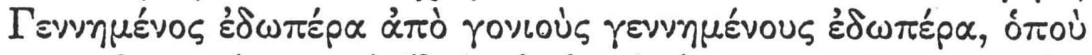

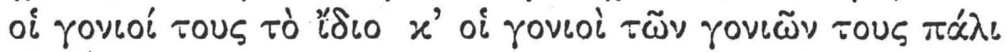

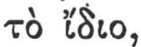

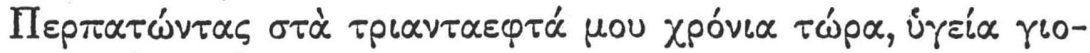

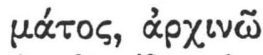

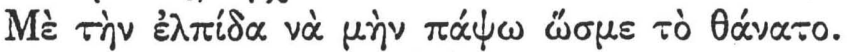

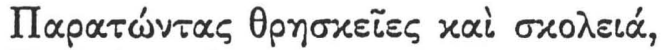

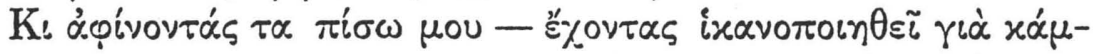

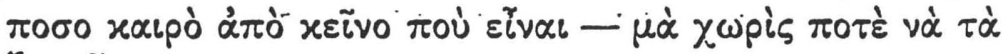
$\xi \Sigma \chi \vee \tilde{\omega}$,

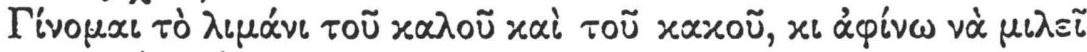
$\sigma \tau \dot{\eta} v \tau u \dot{x} \chi \eta$

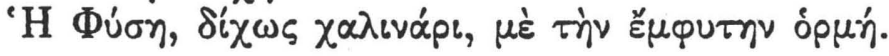


Hebrew:

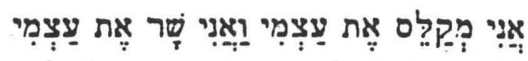

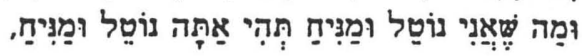

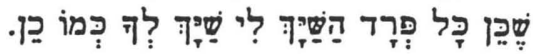

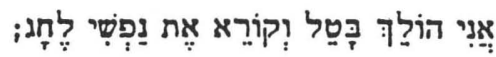

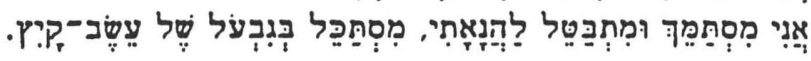

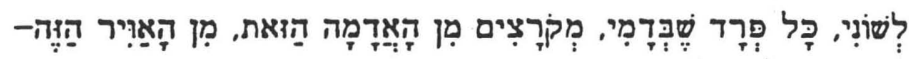

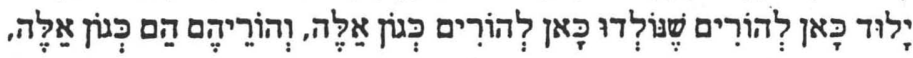

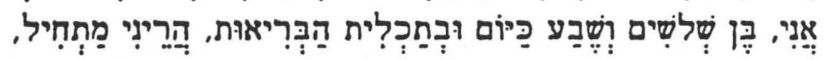

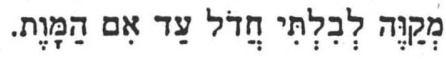

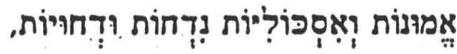

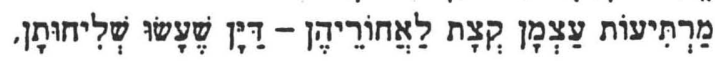

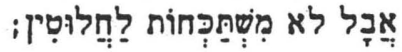

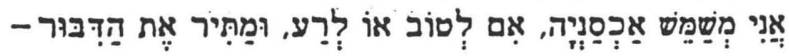

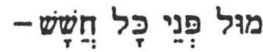

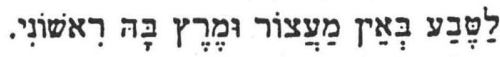

Simon Halkin (1952) 


\section{Hindi:}

\section{मेरा आत्मगीत}

' स्वयं मनाता हूँ मैं उत्सव, स्वयं गीत हूँ गाता । तुम ही धारण वही करोगे, जो मैं धारण करता।

जो कि आवण जो भी मेरा, है उतना हो तुम्हारा //

आमंत्रित कर अपनी आत्मा, घूमा करता रीचि अनुकूल। झुक जाता हूँ और देखता, सहज भाव से घूम घूम कर ग्रिष्म काल का दुर्वाशूल।

मेरे जिह्वा और सक्त के मेरे कण कण। इस मिट्टी से, इस वायु से, जौहैनिर्मित। जन्मा मैं हूँ जो मात पिता से इसी जगह पर । वैसे हो थे मात पिता से वे भी जन्मे । उसी तरह जो मात पिता से वे थे जन्मे । पूर्ण स्वस्थ सैंतीस वर्ष का, श्री गणेश मैं हूँ अब करता। नहीं रूकूँगा मृत्युकाल तक आशा करता /।

संप्रदाय, मत, पथ प्रस्थगित

निवृति कर कुछ काल अंश को ।

उसी रुप में समुचित स्थिति

$$
\text { नही भुला कर किन्तु कमी भी । }
$$

अन्तः स्थल में रख लेता हूँ

हित अथवा अनहित निमिन्त ही ।

अनुमति देता प्रति संकट पर

कह देने की मौलिक ऊर्जा।

पूर्ण प्रकृति निर्बन्ध भाव से // 
Italian:

Io celebro me stesso,

E ogni mia ipotesi dovrà essere la vostra ipotesi,

Poiché ogni atomo che appartiene a me altrettanto appartiene a voi.

Pigramente indugio e invito l'anima mia,

Mi chino e indugio a piacer mio...osservando uno stelo d'erba estiva.

Mario Corona (1996) 
Khmer:

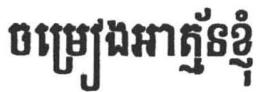

9

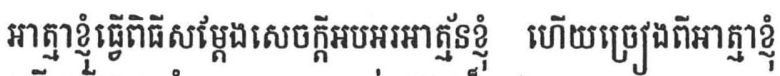

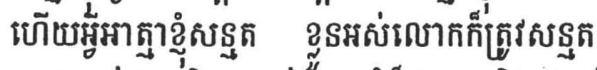

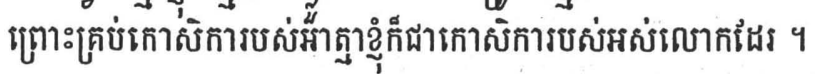

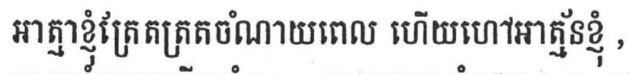

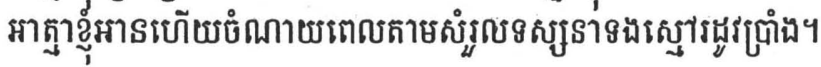

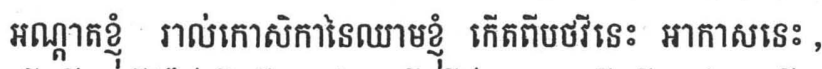

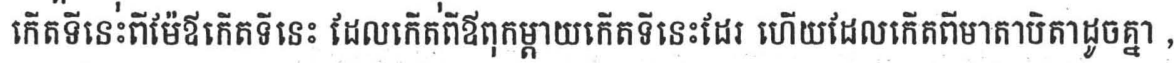

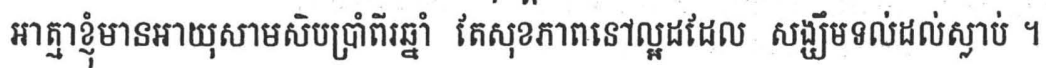

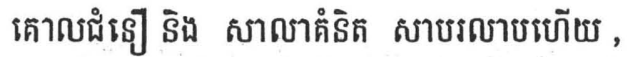

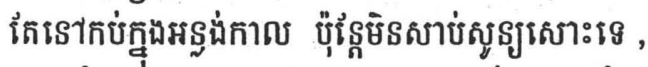

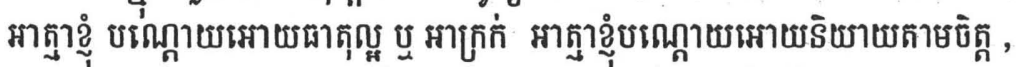

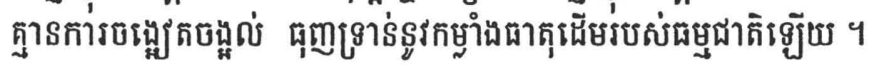


Polish:

\section{Pieśń o sobie}

Siebie czczę i siebie wyslawiam,

I cokolwiek przyjmę, wy przyjmiecie także,

Albowiem każdy mój atom jest również waszym atomem.

Wlóczę się i zachęcam moją duszę,

Włóczę się swobodny, nachylam i oglądam ostrze letniej trawy.

Mój język i każdą krwinkę stworzyly ta gleba i to powietrze,

Tu urodzony, $z$ rodziców tu urodzonych, $z$ takich samych rodziców, a ich rodzice tacy sami,

$\mathrm{Ja}$ - trzydziestosiedmioletni, zdrów jak ryba, zaczynam,

I mam nadzieję nie spocząć do śmierci.

Wiary i szkoły w zawieszeniu,

Wycofują się chyłkiem, rade, że są, czym są, lecz nigdy nie zapomniane, Przygarniam dobro i zło, dopuszczam do głosu bez względu na ryzyko Naturę nieskrępowaną $\mathbf{z}$ jej pierwotną energią. 


\section{Portuguese:}

\section{CANTO A MIM MESMO}

Celebro a mim mesmo

e canto a mim mesmo:

e o que eu assumo, vocês devem assumir, pois cada átomo que a mim pertence

também a vocês pertence.

Folgo e convido minha alma,

deito-me e folgo à vontade vendo no estio uma lança de capim.

Minha língua, cada átomo

do meu sangue, se forma

deste chão, deste ar:

nascido aqui, de pais aqui nascidos

de pais quanto a isso iguais

e os pais deles também,

eu,

agora com trinta e sete anos,

em plena saúde vou

contando não parar

até à morte.

Crenças e escolas em estado latente, por enquanto afastadas um pouquinho, quanto para elas basta, porém não esquecidas, ao bem e ao mal dou guarida e em qualquer circunstância me permito falar - natureza sem confronto com a energia original. 


\section{Russian:}

\section{ПЕСНЯ О САМОМ СЕБЕ}

Я славлю себя и воспеваю себя, И что я принимаю, то примете вы, Ибо каждый атом, принадлежащий мне, также принадлежит и вам. Я, праздный бездельник, зову мою душу, Я стою без забот и, нагнувшись, смотрю на летнюю былинку травы.

Мой язык, каждый атом моей крови созданы из этого воздуха, из этой земли,

Рожденный здесь от родителей, рожденных здесь от родителей, тоже рожденных здесь,

Я, теперь тридцати семи лет, в полном здоровьи, начинаю эту

Надеясь не кончить до смерти.

песню,

Догматы и школы, погодите минуту,

Повремените немного, не бойтесь, мы не забудем и вас.

Я - гавань для доброго и злого, я позволяю природе во всякое

время, всегда

Говорить невозбранно с первобытной энергией. 
Slovenian:

\section{Pesem o sebi}

Opevam sebe in se slavim,

in kar sem jaz dognal, to boš ti dognal,

kajti sleherni atom mojega telesa je tudi del tvojega.

Pohajkujem in pasem svojo dušo, pohajkujem in se brez zadrege sklonim, ko zagledam

bilko poletne trave.

Moj jezik, sleherni atom moje krvi, spočet iz te zemlje, tega zraka,

rojen tu od staršev, prav tako rojenih od staršev in ti prav tako,

začenjam v starosti sedemintridesetih let

in popolnoma zdrav,

v upanju, da do smrti ne presahnem.

Brez prepričanja in šol, za hip odmišljenih $\mathbf{v}$ zadoščenju, a nikoli pozabljenih,

sprejemam dobro in slabo, drznem si govoriti v vsakem trenutku, neobrzdana prvobitna moč narave. 
Spanish:

\section{CANTO DE MI MISMO}

Yo me celebro y yo me canto,

Y todo cuanto es mío también es tuyo,

Porque no hay un átomo de mi cuerpo que no te pertenezca.

Indolente y ocioso convido a mi alma,

Me dejo estar y miro un tallo de hierba de verano.

Mi lengua, cada átomo de mi sangre, hechos con esta tierra, con este aire, Nacido aquí, de padres cuyos padres nacieron aquí, lo mismo que sus padres, Yo ahora, a los treinta y siete años de mi edad y con salud perfecta, comienzo, $\mathrm{Y}$ espero no cesar hasta mi muerte.

Me aparto de las escuelas y de las sectas, las dejo atrás; me sirvieron, no las olvido; Soy puerto para el bien y para el mal, hablo sin cuidarme de riesgos, Naturaleza sin freno con elemental energía.

Jorge Luis Borges (1969) 
Swedish:

\section{SÅNG OM MIG SfÄLV}

Jag firar högtidligt mig själv och sjunger mig själv, Och vad jag tillägnar mig, skall du tillägna dig, Ty varje atom, som tillhör mig, tillhör också dig.

Jag lättjas och inbjuder min själ,

Jag lutar mig och lättjas som jag vill, beskådande ett strå av sommarns gräs.

Min tunga, varje atom av mitt blod, formade ur denna jord, denna luft,

Född här av föräldrar, som fötts här av föräldrar sammaledes, och deras föräldrar sammaledes,

Börjar jag nu, trettiosju år gammal, i fullkomlig hälsa,

Och hoppas att ej sluta förrän i döden.

Trosbekännelser och skolor i bakgrunden,

Medan de draga sig tillbaka en tid, tillräckliga i sig själva, men ej glömda,

Inhyser jag gott och ont och tillåter fritt tal, vad än må ske,

Naturen utan hinder med ursprunglig kraft.

K. A. Svensson (1935) 
Welsh:

\section{CÂN FY HUNAN}

'Rwy'n fy nathlu i fy hun,

A'r hyn a gymeraf arnaf a gymeri dithau arnat,

Oherwydd y mae pob gronyn sy'n perthyn i fi yn eiddo lawn cymaint i tithau.

'Rwy'n loetran ac yn gwahodd fy enaid,

'Rwy'n seguran ac yn loetran yn fy mhwysau, gan graffu ar wayw glaswelltyn yr haf.

Mae tai a stafelloedd yn llawn peraroglau, mae'r silffoedd yn drwch o beraroglau,

'Rwy'n anadlu'r persawr fy hun, a'i nabod a'i hoffi,

Fe fyddai'r distylliad yn fy ngwneud innau'n feddw, ond wna'i ddim gadael iddo.

Nid perarogl yw'r aer, 'does dim o flas y distylliad arno, mae e'n ddiarogl,

Mae e' at fy nant i am byth, 'rwy' wedi ffoli arno,

$\mathrm{Fe}$ af $\mathrm{i}$ at y bencyn ger y coed, fe gaf wared ar bob ffug ac ymddinoethi,

'Rwy'n wyllt am glywed ei gyffyrddiad.

M. Wynn Thomas (1995) 
Sources for Translations of Section 1 of "Song of Myself":

Chinese: Cao Ye fi. Shanghai: Shanghai Translation Press, 1992.

French: Chants de la terre qui tourne, poèmes et proses de Walt Whitman. Paris: Nouveau Horizons, 1966.

German: Walt Whitmans Werk. Berlin: S. Fischer, 1922.

Greek: Phylla Chloes. Athens: "Hestia," 1950.

Hebrew: Ale Esev. Tel Aviv: Sifriat Poalim, 1952.

Hindi: Durvadal. 1992.

Italian: Foglie d'erba. Venice: Marsilio, 1996.

Khmer: Walt Whitman's "Song of Myself," parts 1-8, and "I Hear America Singing.” Iowa City: Zephyr Limited Editions Chapbook, 1995.

Polish: Piesn o Sobie. Kraków: Wydawnictwo Literackie, 1992.

Portuguese: Folhas das Folhas de Relva. São Paulo: Brasiliense, 1983.

Russian: List'ya Travy, Proza. Petersburg: "World Literature," Gos. Izd., Tip. 15-ya Gosudarstvennaya, 1922.

Slovenian: Lirika. Ljubljana: Mladinska Knjiga, 1989.

Spanish: Hojas de hierba. Buenos Aires: Juárez, 1969.

Swedish: Strån av Gräs. Stockholm: A.B. Seelig, 1935.

Welsh: Dail Glaswelt: Eltholiad o Gerddi Walt Whitman. Cardiff: Yr Academi Gymreig, 1995. 